\title{
Possible selves as roadmaps
}

\author{
Daphna Oyserman, ${ }^{\mathrm{a}, *}$ Deborah Bybee, ${ }^{\mathrm{b}}$ Kathy Terry, ${ }^{\mathrm{a}}$ \\ and Tamera Hart-Johnson ${ }^{\mathrm{a}}$ \\ a The University of Michigan, Institute for Social Research, 426 \\ Thompson Avenue, room 5240, Ann Arbor, MI 48106-1248, USA \\ b Michigan State University, USA
}

\begin{abstract}
Possible selves, expectations, and concerns about the coming year, can promote feeling good ("I may not be doing well in school this year, but I will next year.") or can promote regulating for oneself ("I may not be doing well in school this year, but to make sure I do better next year, I have signed up for summer tutoring."). We hypothesized that improved academic outcomes were likely only when a possible self could plausibly be a self-regulator. Hierarchical regression analyses supported this conclusion, with more support for the influence of self-regulation on change in behavior and academic outcomes than on affect regulation. $N=160$ lowincome eighth graders improved grades, spent more time doing homework, participated in class more, and were referred less to summer school (controlling for fall grades and the dependent variable of interest) when academic possible selves were plausibly self-regulatory.

(c) 2003 Elsevier Science (USA). All rights reserved.
\end{abstract}

Keywords: Possible selves; Self-regulation; Identity; Adolescence; Minority; African American; Hispanic; Academic; School; Motivation

\section{Introduction}

Next year, I expect to be... "13 years old, playing football (I am going to practice this year), in high school, playing basketball (I am coming to my games this year)." Next year I want to avoid... "drugs (I am getting away from that, not doing drugs this year), being killed (I am getting away from people that are crazy this year)." (Possible selves of an inner city eighth grader, fall of eighth grade, with strategies noted in parentheses.)

\footnotetext{
${ }^{*}$ Correponding author. Fax: 1-734-647-3652.

E-mail address: daphna.oyserman@umich.edu (D. Oyserman).
} 


\begin{abstract}
Next year, I expect to be... "getting good grades in school (I am staying out of trouble and not talking too much this year), going to high school (I am paying attention in class and doing my work this year)." Next year, I want to avoid... "Failing 8th grade (I am not skipping class and am doing my work this year), dropping out of high school (I am not being lazy and not getting in trouble this year)." (Possible selves of an inner city eighth grader, fall of eighth grade, with strategies noted in parentheses.)

Next year I expect to be... "going to high school (I am studying and doing good in the 8th grade), going to King High School (by turning in my high school application and preparing for the test), studying well and passing all my grades (by not getting in trouble and being serious about my studies)." Next year I want to avoid. .. "Being a class clown (by listening to the teacher and being quiet in class), not having good grades" (by studying and doing my work), and going the wrong direction in life (by being serious about school)." (Possible selves of an inner city eighth grader, fall of eighth grade, with strategies noted in parentheses.)
\end{abstract}

These are written responses of eighth graders to questions about what they expect to be like next year, what they want to avoid being like next year, and, in parentheses, their responses to the follow-up question for each possible self, "Is there anything you are doing now to get to be this way (or to avoid becoming this way)?" While all three youths mention being in high school, the question motivating our research was whether these possible selves were equally effective in maintaining positive affect, sustaining goal focused behavior, and fostering successful academic outcomes over the course of the school year. A number of authors have argued that having a self-relevant plan, goal, possible self, or personal striving in a domain should improve self-regulation (for reviews see Markus \& Wurf, 1987; Oyserman, 2001). Indeed, having a plan focuses attention; goal-focused individuals are more likely to ignore information irrelevant to their chosen goals, which allows for more focus on the goal (Gollwitzer, 1996).

While in laboratory settings, shifts in goals, personal strivings, or self-motivation clearly influence mood, behavior, and outcomes (Coats, Janoff-Bulman, \& Alpert, 1996; Rawsthorne \& Elliott, 1999), in more naturalistic settings, personal striving, possible selves, goals or resolutions are often vague and not connected with action plans that detail when, where, and how to proceed toward the goal. To regulate behavior, the self-concept must contain not only goals or desired end states, but also strategies about how to behave in order to reach the desired end state (e.g., 'I can make it to high school by paying attention in class' (Higgins, 1996)). Perhaps it should come as no surprise, then, that people often fail to attain their goals (Gollwitzer, 1996).

Goals, strivings, and possible selves may serve functions other than self-regulation. They can facilitate optimism and belief that change is possible because they provide the sense that the current self is mutable (Markus \& Nurius, 1986). Thus goals or possible selves may simply make us feel good about ourselves, particularly if the goal or future self is vague and carries no specified action plan (Gonzales, Burgess, \& Mobilio, 2001). Indeed, a dominant self-goal is simply to feel good about the self-to self-enhance (Brown, 1998). By allowing one to feel good about the self and providing hope for a better future, personal strivings, possible selves, and other future oriented aspects of self-concept may fulfill self-enhancement goals. For example, a student may say to herself, 'I may not be doing well in school now but I will 
succeed next year,' in this way buffering self-esteem from current bad grades, though not engaging in any behavioral strategies to actually increase the chance of earning better grades in the coming year.

Supporting this notion, Gonzales et al. (2001) found that articulating a goal elevated mood, improved well being and created a sense of optimism about the likelihood of attaining the goal for participants, compared with participants who did not articulate a goal. Self-enhancing possible selves promote positive feelings and maintain a sense of optimism and hope for the future without evoking behavioral strategies.

Yet there is also evidence that setting goals and raising aspiration can improve performance. Through self-directed goals, we can harness motivation and direct action toward self-improvement (Brickman \& Bulman, 1977; Taylor, Neter, \& Wayment, 1995). In this sense, possible selves and other self-directed goals can serve to guide and regulate behavior, providing a roadmap connecting the present to the future. The more plans connect self-directed goals to specific strategies; the more likely they are to be carried out (Gollwitzer, 1996). Indeed there is evidence that even relatively straightforward self-regulation strategies like telling oneself 'pay attention' or 'work hard' can influence outcomes in laboratory settings (Gollwitzer, 2002). In the current paper, we focus on youths living in high poverty neighborhoods and attending urban schools with mostly low-income minority peers. We ask if detailed academic possible selves that contain strategies for working on them will succeed in promoting successful academic engagement - a sense of connection to school, on-task behavior in class, and better grades, even among youths at high risk of academic failure or whether it is enough to have many academically oriented possible selves.

To study the effects of self-regulatory possible selves, we focus on academic possible selves among low-income adolescents for a number of reasons. We focus on academics because school is a central domain of adolescence and success in school provides a basis for a successful transition into adulthood. A number of studies suggest that school, education, and future occupations are among the most common foci of young teens' possible selves (Knox, Funk, Elliott, \& Bush, 2000; Shepard \& Marshall, 1999), and that students who see school as central to their future success have higher current well-being (Cameron, 1999).

We focus on minority youths because self-regulation of academic behavior may be particularly important for youths facing stereotypes about their academic interest and abilities. Without the ability to self-regulate, these youths may be particularly vulnerable to stereotype threat (Steele, 1997). Moreover, qualitative research suggests variability in focus on school success among minority groups (Kao, 2000). We focus on adolescence because a focus on the future is intrinsic to the social role of adolescence. Adolescent self-concepts are open to social feedback from peers, the media, parents, and other adults. Youths actively seek evidence of who they might become through social interactions, the responses of others to their behavior, as well as from role models and internalized standards (Harter, 1985).

Indeed, some possible selves are quite malleable, shifting in response to feedback either about one's own likely success in attaining the possible self (Kerpelman \& 
Pittman, 2001) or similar others' successes and failures in attaining the possible self (Kemmelmeier \& Oyserman, 2001). These possible selves are unlikely to serve selfregulatory functions. We speculate, however, that when young adolescents feel committed to and invested in working toward attaining possible selves and link current behaviors to attainment of these future goals, then possible selves can serve a selfregulatory role. By both focusing attention on a self-defining goal and linking the goal to current action, these 'self-regulating' possible selves can preserve positive affect, maintain behavioral focus, and ultimately propel the self toward the goal, in contrast to self-enhancing possible selves that do not.

Research to date has not disentangled the self-enhancing and self-regulatory functions of possible selves, focusing instead on describing content of possible selves and correlating content with outcomes more generally, for example assessing the frequency that positive and negative academic possible selves are generated and the correlation between that and academic success or involvement in delinquent activities (cf. Aloise-Young, Hennigan, \& Leong, 2001; Oyserman \& Markus, 1990). Even when a more complex coding strategy is used - such as the work focused on 'balance' in possible selves (Oyserman \& Markus, 1990), how the regulatory focus of possible selves would be instantiated was given short shrift. Rather than simply focus on whether youths mention success in school as a self-goal, or whether they mention both an expectation of success and a concern about failure, we hypothesized that academic possible selves differ in whether they are 'self-regulating' or 'self-enhancing' possible selves. We propose that academic possible selves will guide behavior and produce the intended regulatory consequence over time only when they are detailed and contain strategies for carrying out the goal. Thus, we propose that self-regulation is best achieved when possible selves are detailed and contain strategies for both personal goal focused action and for dealing and engaging with the social context in which the goal is to be achieved. For example, the possible selves of the eighth graders quoted above all include being in high school, yet only the latter two youths describe specific strategies for succeeding in school ("paying attention in class and doing my work this year") and avoiding failure ("I am not being lazy and not getting in trouble this year.") Conversely, the first youth envisions being in high school but lacks any strategies to insure success or to avoid failure in this domain. Moreover, only the third youth describes self-regulation focused on the social context of school-proposing to avoid being the class clown by listening to the teacher and being quiet in class. While all youths have possible selves about being in high school, only one of the youths has a detailed possible self beyond the broad sketched outlines of high school ("going to King High School," "studying well and passing all my grades") noting which high school and what the self would be doing at that high school.

In the current study, we examine these differences in the ways that possible selves are instantiated, predicting that only possible selves that are detailed and connected with specific behavioral strategies can sustain self-regulation over time and therefore be guides for self-improvement. We propose that vague, general possible selves lacking behavioral strategies cannot function to guide self-regulation because they neither provide a specific picture of one's goals nor a roadmap of how to reduce 
discrepancies between the present and one's future possible selves (Carver, 2001). We are particularly interested in the impact that possible selves have on academic outcomes among otherwise disadvantaged youths - minority youths attending inner city public schools and living in low-income neighborhoods. These youths must figure out a plan of action to succeed in school in spite of these risk factors as well as risks from stereotypes about their interest in school, their academic ability, and their likelihood of succeeding in the world of work beyond school. Therefore, for these youths, having detailed academic possible selves that engender self-regulation and articulate strategies that take into account the social context of school may be particularly critical mechanisms of sustaining positive affect about school, positive behavioral engagement with school and school activities, and in the end, more success in school-obtaining better grades and reducing risk of school failure.

\subsection{Hypothesis}

Youths whose academic possible selves are self-regulating (provide a better road map for guiding affect and behavior) will be more successful in the domain of school. Specifically, youths with more self-regulatory academic possible selves will: (a) be better able to focus positive affect on school, (b) be more involved in classroom activities, (c) spend more time doing homework, (d) obtain better grades, and (e) be less at risk of referral to remedial summer school, resulting in improvement in these areas compared with their peers who have less self-regulatory academic possible selves. Since our focus is on self-regulatory academic possible selves - that is, detailed academic possible selves that contain strategies to promote self-regulation, rather than the simple presence of academic possible selves, we propose that (f) self-regulatory academic possible selves will be a better predictor of school success than a simple count of the number of academic possible selves or an assessment of the extent that academic possible selves are balanced - containing both a positive expectation and a fear or concern in the same domain. Finally, while self-regulation can be operationalized simply as a count of academic strategies, we examine the extent that the combination of detailed academic possible selves and strategies adds predictive power.

\section{Method}

\subsection{Sample}

Students were a randomly selected half of the eighth grade cohort in three inner city middle schools serving low-income families $(67.3 \%$ of students at the schools received free or reduced-price lunch). Students enrolled in these schools came from 105 mostly ethnic minority and high poverty census tracks. That is, in these census tracks, $34 \%$ of households had incomes below the poverty line, $57 \%$ of households were headed by African Americans and 23\% were headed by Hispanics; $43 \%$ of the adults had less than a high school education, and only $43 \%$ of adults were employed (US Bureau of the Census, 2000). 


\subsection{Procedure}

Of the 168 students randomly selected, written parental approval (for the youth to participate in the survey, to allow the school to release grades and to have a core subject teacher rate the youth's in-class behavior) was obtained for 160 youths, 81 boys and 79 girls. According to student report, students were African American $(n=99)$, Hispanic $(n=41)$, and non-Hispanic white $(n=20)$. As part of a larger study, students filled out a questionnaire in the beginning and end of the school year; at the same time, teachers rated student behavior and our research staff obtained school records of grades and, at the end of the school year, information about referral to remedial summer school. To minimize attrition, an intensive tracking protocol was used to follow youth and obtain spring data for students who left or transferred school. Therefore, missing data were minimal and appeared to be randomly distributed across the data matrix (Little's MCAR chi-square statistic $\chi^{2}$ $(d f=241)=267.01, p=.12)$. In order to use all cases in the multivariate analysis, missing values were estimated using expectation maximization (Schafer \& Graham, $2002) ; 12.4 \%$ of the values in the data matrix were estimated.

\subsection{Measures}

Positive affect toward school is an 11-item 5-point Likert scale (1, strongly disagree and 5, strongly agree) (Arroyo \& Zigler, 1995; Cernkovich \& Giordano, 1992). Sample items are "I feel I really belong at school" and "I wish I could drop out of school" (reverse coded) (fall $M=3.94, S D=0.59, \alpha=0.75$ and spring $M=3.89$, $S D=0.63, \alpha=0.78)$.

Participation in class is a 4-item 5-point (1, never and 5, always) participation scale from the Finn Student Participation Questionnaire (Finn, Pannozzo, \& Voelkl, 1995; eighth grade revision J.D. Finn, personal communication, October 14, 1998). Items were "This student pays attention in class," "This student completes homework and in-class assignments," "This student is persistent when confronted with difficult problems," "This student seems to think this course is valuable." A core subject teacher rated these items for each student in the study (fall $M=3.28$, $S D=0.73, \alpha=0.65$ and spring $M=3.11, S D=0.75, \alpha=0.77)$.

Time spent doing homework is a single question, "How many hours a week do you spend doing homework?" (fall $M=4.37, S D=4.68$ and spring $M=3.56$, $S D=3.03)$.

Archival grade point average. Report cards were collected directly from schools. Grade point average, as calculated from letter grades in at least three courses, was calculated following the typical 5-point scale where $A=4, B=3, C=2, D=1$, and $F=0$ (fall $M=2.13, S D=0.79$ and spring $M=2.07, S D=1.00$ ).

Referral to remedial summer school is a dichotomous variable determined from school lists of students who would be required to attend summer school in order to be passed to the 9 th grade. Students could be referred for not passing at least 3 of the 4 Essential Skills Attainment Tests, for failing grades, or for low attendance. Students were coded as " 1 " if referred $(n=89)$ and " 0 " $(n=71)$ if not. 
Self-regulation. To obtain fall self-regulation scores, the following protocol was used. First, we asked youth to generate expectations and concerns for the coming year, and to describe any strategies they had for working toward their expected and away from their feared or to-be-avoided next year possible selves (for specific question wording and format, see Appendix A). Second, we categorized expected and feared possible selves and any strategies for attaining them into one of six domains: school achievement, interpersonal relationships, personality traits, physical/ health, material/lifestyle, or negative (for expected selves) or non-normative/delinquent (for feared selves). Third, we coded the extent to which achievement possible selves and the strategies connected to them were plausibly self-regulating on a 6point scale; with lower scores indicating a combination of few possible selves and strategies, and higher scores indicating a combination of more possible selves and strategies. Higher scores indicate higher likelihood that self-regulation would occur, with the difference between scores of 4 and 5 being that level 4 strategies focused on academic achievement, while at least some of the level-5 strategies focused on the social context of academic achievement $(M=2.21, S D=1.28$, range $=0-5)$. An example of a 5-level self-regulatory response is "Next year I expect to... go to high school (study and do good in the 8th grade), I will go to King High School (by turning in my high school application and preparing for the test), I will study well and pass all my grades (by not getting in trouble and being serious about my studies). Next year I want to avoid. . Being a class clown (by listening in school and being quiet), not having good grades (by studying and doing my work), and going the wrong direction in life (by being serious about school)." Five coders blind to other youth responses each worked on a randomly assigned subset of the possible self-responses, with one third of each coder's interviews randomly selected to be double coded by another coder; across all double coding, we obtained a $94 \%$ agreement rate. A summary of the coding scheme is provided in Table 1 and the full coding manual is available from the first author.

As an alternative, simpler procedure for examining self-regulation that does not require detailed content coding, a count of strategies to attain expected and avoid feared achievement possible selves was also obtained, $M=2.43, S D=1.99$. Number of strategies to attain expected and avoid feared achievement-related possible selves is related to the above coding system, but does not take into account the number or detail of possible selves or whether the strategies do or do not contain the social context of achievement. By pitting this more straightforward count against the content-coded score, the possibility that future research can be carried out with a less extensive coding process but still utilize the notion that self-regulation predicts behavior change and maintenance of positive affect over time can be explored.

Achievement possible selves. In addition to the analyses of the predictive power of self-regulation, we also pitted self-regulation with possible selves, coded either as a simple count of the number of expected and to-be-avoided academic possible selves, $M=3.23, S D=1.58$ (Coding manual available from the first author), or as balanced achievement possible selves. Total number of balanced achievement possible selves were the number of pairs of expected and to-be-avoided achievement possible selves that contained opposite sides of the same achievement issue, $M=0.42$, $S D=0.55$. An example is "Next year I expect to be in high school; next year I want 
Table 1

Self-regulation coding chart

\begin{tabular}{|c|c|c|c|}
\hline $\begin{array}{l}\text { Self-regulation } \\
\text { score }\end{array}$ & $\begin{array}{l}\text { No. of } \\
\text { expected or } \\
\text { feared } \\
\text { academic } \\
\text { possible } \\
\text { selves (APS) }\end{array}$ & $\begin{array}{l}\text { No. of } \\
\text { strategies } \\
\text { attached to } \\
\text { these APS }\end{array}$ & Coding operationalization \\
\hline \multirow[t]{2}{*}{0} & 0 & & $\begin{array}{l}0-1 \text { APS AND } 0 \text { APS strategy (Ex: Next year I } \\
\text { expect to be... "in high school") }\end{array}$ \\
\hline & 1 & 0 & \\
\hline \multirow[t]{2}{*}{1} & 1 & 1 & 1 APS and 1 APS strategy OR 2 APS but no APS \\
\hline & 2 & 0 & $\begin{array}{l}\text { strategies (Ex: Next year I expect to be... "in high } \\
\text { school (I'm doing my work)") }\end{array}$ \\
\hline \multirow[t]{4}{*}{2} & 1 & $2 *$ or more & 1 APS and 2 or more APS strategies* OR 2 APS \\
\hline & 2 & $1-2$ & and $1-2$ APS strategies OR 3 APS and $0 *-1$ APS \\
\hline & 3 & $0 *-1$ & strategies OR 4 or more APS and 0 APS strategies \\
\hline & 4 or more & 0 & $\begin{array}{l}\text { studying harder)" Next year I expect to avoid... } \\
\text { "failure (I am doing my best)") }\end{array}$ \\
\hline \multirow[t]{2}{*}{3} & 2 & $3^{*}$ or more & 2 APS and 3 or more APS strategies* OR 3 APS \\
\hline & $\begin{array}{l}3 \\
4 \text { or more }\end{array}$ & $\begin{array}{l}2-3 \\
1 *-2\end{array}$ & $\begin{array}{l}\text { and } 2-3 \text { APS strategies OR } 4 \text { or more APS and } \\
1 *-2 \text { APS strategies (Ex: Next year I expect to be... } \\
\text { "In Cass Tech High School (by studying harder), an } \\
\text { all A and B student (by making it a goal to get all A's } \\
\text { now)," I plan to avoid... "getting bad grades (by } \\
\text { trying more and more)") }\end{array}$ \\
\hline \multirow[t]{2}{*}{4} & 3 & 4 or more & 3 APS and 4 or more APS strategies OR 4 APS and \\
\hline & 4 or more & $2 *$ or more & $\begin{array}{l}\text { 2*-4 APS strategies (Ex: Next year I expect to be... } \\
\text { "A straight A student (by studying at night), a high } \\
\text { schooler (by practice writing and doing my best)", } \\
\text { Next year I expect to avoid. . " failing a grade (by } \\
\text { doing all my work), dropping out of school (by trying } \\
\text { to do my best)") }\end{array}$ \\
\hline 5 & 4 or more & $4-5+$ & $\begin{array}{l}4 \text { or more APS AND } 4 \text { or more APS strategies } \\
\text { AND at least one APS strategy is focused on the } \\
\text { interpersonal aspects of school context. (Ex: Next } \\
\text { year I expect to... "go to high school" (study and do } \\
\text { good in the 8th grade), "I will go to King High } \\
\text { School' (by turning in my high school application } \\
\text { and preparing for the test) "I will study well and pass } \\
\text { all my grades" (by not getting in trouble and being } \\
\text { serious about my studies). Next year I want to } \\
\text { avoid... "Being a class clown" (by listening in school } \\
\text { and being quiet), "not having good grades" (by } \\
\text { studying and doing my work), and "be serious about } \\
\text { school" (by telling my friends they can skip if they } \\
\text { want to. Not me.")) }\end{array}$ \\
\hline
\end{tabular}

Note. * means code at this level only if at least one of the APS and APS strategies are detailed and concrete, that is if a specific action is implied and the APS are not redundant, otherwise code at the next lower self-regulation score.

Examples provided represent the full APS response of the youth to the possible self instrument presented in Appendix A. APS are presented first, followed by the APS strategy in parenthesis. 
to avoid still being in the eighth grade." Balance has been argued to increase motivational persistence. To code for balanced academic possible selves, we used the method described by Oyserman and Markus (1990).

\section{Results}

\subsection{Analysis plan}

To examine the effects of self-regulatory academic possible selves on positive affect in school, participation in class, time spent doing homework, grades, and risk of repeating eighth grade, we utilized a series of hierarchical regression equations, one for each dependent variable. For each dependent variable, we followed the same order of entry for the blocks of independent variables. At block one, we entered dummy variables for sex and race (white and Hispanic, with African American as the omitted category); at block two we entered fall grade point average from school records; at block three we entered the fall measure of each dependent variable being studied. At block four we entered the fall score for self-regulatory academic possible-selves. By including both fall GPA and the fall level of the outcome variable, we focused on the effect of self-regulation on change during the school year, providing a conservative estimate of the effect of self-regulation, net of general academic success or previous attainment in the domain. To test the alternative hypotheses that simple count of academic strategies, academic possible selves or number of 'balanced' academic possible selves predicts change in academic outcomes, we repeated all of the above analyses three times, once using at the final block the count of the number of academic possible self-strategies, a second time using a count of the number of academic possible selves and a third time using number of 'balanced' academic possible selves at the final block. These analyses allowed us to compare the predictive power of self-regulation (with two alternative coding strategies) with that of the centrality of academic possible selves on self-concept (coded in ways that do not disentangle self-enhancement from self-regulatory focus). Two final sets of analyses included: (a) both number of academic strategies and, at the final step, academic self-regulation to provide a stringent test of the predictive power of the more inclusive yet more complex coding scheme and (b) both balance in academic possible selves and, at the final step, academic self-regulation, to provide a stringent test of the added predictive power of self-regulation over and above the effects of balanced academic possible selves. In each case we used a one-tailed criterion, following the directional nature of our hypotheses.

Because all outcomes focus on school, we examined their correlation (presented in Table 2) for both fall and spring. Although correlated, outcome variables are not redundant, and each focuses on a substantively different self-regulatory function-maintaining positive affect, behavioral engagement (in class, spending time at home on schoolwork), attaining the desired outcomes (attaining good grades and avoiding school failure). Moreover, these dependent variables were collected from three different sources: self-report, teacher report, and school records. There- 
Table 2

Correlations among dependent variables

\begin{tabular}{llllc}
\hline & $\begin{array}{l}\text { Positive } \\
\text { affect }\end{array}$ & $\begin{array}{l}\text { Class } \\
\text { participation }\end{array}$ & Homework & GPA \\
\hline Positive affect about school & - & $.37^{* * *}$ & -.03 & $.35^{* * *}$ \\
Teacher reported participation in class & $.27^{* * *}$ & - & -.04 & $.58^{* * *}$ \\
Student reported time spent doing homework & $.20^{*}$ & $.25^{* *}$ & - & -.09 \\
School records report of GPA & $.27^{* * *}$ & $.62^{* * *}$ & $.23^{* *}$ & - \\
School reported summer school referral & $-.27^{* * *}$ & $-.51^{* * *}$ & $-.13^{\dagger}$ & $-.54^{* * *}$ \\
\hline
\end{tabular}

Note. Correlations above the diagonal are for fall; those below the diagonal are for spring.

${ }^{*} p<.05$.

${ }^{* *} p<.01$.

${ }^{* * *} p<.001$.

${ }^{\dagger} p<.10$.

fore we report each finding with a separate regression equation. As a check of the robustness of our findings to different methods of analysis, we also conducted a multivariate set correlation (Cohen, 1982), predicting the entire set of outcome variables from the self-regulation plausibility score, after accounting for the effects of sex, race, and fall values on the outcomes-grades, homework time, class participation and positive affect toward school. This analysis tests the null hypothesis of no overall relationship between self-regulation plausibility and the set of outcome variables, controlling for the set of control variables. Confirmation of effects with both methods strengthens confidence that results are not due to capitalization on chance.

\subsection{Descriptive analyses}

We first explored the extent to which the academic domain was indeed central to youths' possible selves. On average, $82 \%$ of expected selves were focused on the achievement domain (2.36 of 2.88), as were $82 \%$ of strategies to attain expected selves (1.80 of 2.19). Similarly, $36 \%$ of feared or to-be-avoided possible selves focused on the achievement domain ( 0.87 of 2.39 ), as were $36 \%$ of strategies to avoid becoming like these feared selves $(0.63$ of 1.76$)$. While the academic domain was a less common focus of feared than of expected possible selves, it was still the most common domain for feared possible selves. Therefore, attention to plausible academic possible selves can be said to focus on a central self-regulatory concern in this age period.

Despite the centrality of the academic domain to youths' possible selves, academic participation declined significantly over the school year, lending credence to our focus on 'self-regulatory' as opposed to non-self-regulatory possible selves. Specifically, teacher rated student classroom participation declined significantly (fall $M=3.28$, spring $M=3.11, t(159)=-2.98, p<.001)$, as did hours spent doing homework each week (youth report) (fall $M=4.37$, spring $M=3.56, t(159)=-2.20$, $p=.03$ ). Only archival grade point average (fall $M=2.13$, spring $M=2.07$, 
$t(159)=-1.18, p=.24)$ did not decline significantly. As can be seen in Table 4, girls participated more in class than boys. Participation rates did not vary by race, but the other measures of academic outcome did, with African Americans spending more time in homework, obtaining better grades and being at lower risk of referral to remedial summer school.

\subsection{Influence of self-regulation on change in affect, behavior, and academic outcomes}

The full model is provided in Table 3, where we report change in variance explained at each block, statistical tests of the contribution of each block, and the final model. Regression weights for each of the dependent variables in the final model are presented in Table 4. For ease of reading, in the following section, we discuss only the significant increase in variance explained at the final block with the addition of the self-regulation plausibility score.

Positive affect toward school. Using our self-regulation scoring system, we did not find the hypothesized effect of self-regulation on maintenance of positive affect for school, controlling for grades, and level of school bonding in the fall, $R^{2} \Delta=.00$, $F \Delta(1,154)=0.04, p=.41 ; B=0.01, \beta=0.01$.

Participation in class. As hypothesized, controlling for grades and classroom participation in the fall, students with higher academic possible-self-regulation scores in the fall were rated by their teachers in the spring as participating more in classroom activities: $R^{2} \Delta=.01, F \Delta(1,153)=3.20, p=.04 ; B=0.06, \beta=0.11$.

Time spent doing homework. As hypothesized, controlling for grades and time spent on homework in the fall, students with higher academic possible-self-regulation scores in the fall reported spending more time doing homework in the spring, $R^{2} \Delta=.04, F \Delta(1,153)=8.17, p<.01 ; B=0.49, \beta=0.20$.

Archival grade point average. As hypothesized, controlling for fall grades, students with higher academic possible-self-regulation scores in the fall attained higher grade point averages in the final marking period of the school year, $R^{2} \Delta=.01$, $F \Delta(1,154)=5.11, p=.01 ; B=0.09, \beta=0.12$.

Referral to remedial summer school. As hypothesized, controlling for fall grades, students with higher academic possible-self-regulation scores in the fall were less likely to be referred by their school to attend remedial summer school classes in the spring. Because referral to summer school is a dichotomous variable, this analysis used hierarchical logistic regression following the same order of entry of blocks as previously described. Wald test for possible-self-regulation score $=2.87, \chi^{2}(1$, $n=160$ ) for block $=2.93, p=.04 ; B=-0.26, \exp (B)=0.77$.

Multivariate set correlation. Multivariate analysis confirmed that self-regulation accounted for significant variance in the five academic outcomes considered together, after accounting for the effects of the set of five control variables (race, gender, fall GPA, fall participation, and fall homework)-multivariate Rao's $F(5,148)=2.59$, $p=.028$. Self-regulation accounted for $8 \%$ of the multivariate variance across the set of five spring academic outcome variables. This significant finding strengthens confidence that the significant findings across the outcome variables are not due to chance. 
Table 3

Self-regulation predicting academic outcomes: hierarchical regression block summary table

\begin{tabular}{|c|c|c|c|c|}
\hline $\begin{array}{l}\text { Independent variables, } \\
\text { by block }{ }^{\mathrm{c}}\end{array}$ & $R^{2}$ & $\Delta R^{2}$ & $\Delta$ Statistic & Final model statistic \\
\hline \multicolumn{5}{|c|}{ Positive affect toward school } \\
\hline 1. Gender, race & .12 & .12 & $F=6.98^{* * *}$ & \\
\hline 2. 1st Q GPA & .13 & .02 & $F=2.71^{\dagger}$ & \\
\hline 3. Fall positive affect & .31 & .18 & $F=38.96^{* * *}$ & \\
\hline 4. Self-regulation & .31 & .00 & $F=0.04$ & $F(6,153)=11.38^{* * *}$ \\
\hline \multicolumn{5}{|l|}{ Participation $^{\mathrm{a}}$} \\
\hline 1. Gender, race & .08 & .08 & $F=4.78^{* *}$ & \\
\hline 2. 1st Q GPA & .43 & .34 & $F=92.20^{* * *}$ & \\
\hline 3. Fall participation & .46 & .04 & $F=10.52^{* * *}$ & \\
\hline 4. Self-regulation & .47 & .01 & $F=3.20^{*}$ & $F(6,153)=22.93^{* * *}$ \\
\hline \multicolumn{5}{|l|}{ Homework $^{\mathrm{a}}$} \\
\hline 1. Gender, race & .08 & .08 & $F=4.67^{* *}$ & \\
\hline 2. 1st Q GPA & .08 & .00 & $F=0.16$ & \\
\hline 3. Fall homework & .21 & .13 & $F=24.59^{* * *}$ & \\
\hline 4. Self-regulation & .25 & .04 & $F=8.17^{* *}$ & $F(6,153)=8.49^{* * *}$ \\
\hline \multicolumn{5}{|l|}{ 4th $Q G P A^{\mathrm{a}}$} \\
\hline 1. Gender, race & .16 & .16 & $F=9.69^{* * *}$ & \\
\hline 2. 1st Q GPA & .58 & .43 & $F=157.74^{* * *}$ & \\
\hline 3. Self-regulation & .60 & .01 & $F=5.11^{*}$ & $F(5,154)=45.37^{* * *}$ \\
\hline \multicolumn{5}{|l|}{ Summer school ${ }^{\mathrm{b}}$} \\
\hline 1. Gender, race & .09 & $\chi^{2}=10.82^{* *}$ & & \\
\hline 2. $1^{\text {st }} \mathrm{Q}$ GPA & .30 & $\chi^{2}=30.42^{* * *}$ & & \\
\hline 3. Self-regulation & .33 & $\chi^{2}=2.93^{*}$ & $\chi^{2}(5)=44.17^{* * *}$ & \\
\hline
\end{tabular}

All tests are one-tailed.

${ }^{\text {a }}$ Analyses are ordinary least squares regressions.

${ }^{\mathrm{b}}$ Referral to summer school is a dichotomous variable, so logistic regression analysis was used; reported $R^{2}$ statistic is Nagelkerke $R^{2-}$ analogous, but not directly comparable statistic to the $R^{2}$ statistic used in the OLS regressions.

${ }^{\mathrm{c}}$ For each model, 2 way interactions between plausibility and race and between plausibility and gender were explored. Because none was significant, they are not presented in the table.

${ }^{*} p<.05$.

${ }_{* * *}^{* *}<<.01$

$p<.001$.

${ }^{\dagger} p=.10$.

Alternate coding of self-regulation as number of achievement strategies. To test the alternative, simpler operationalization of self-regulation as the number of strategies related to achievement possible selves, we followed the same procedure, substituting number of strategies for the more complex coding of self-regulation. The more complex coding of self-regulation was a somewhat better predictor than the simpler operationalization as number of strategies related to achievement possible selves. Specifically, number of achievement strategies predicted positive affect toward school $\left(R^{2} \Delta=.02, F \Delta(1,154)=4.55, p=.01 ; B=0.05, \beta=0.15\right)$, grades $\left(R^{2} \Delta=.03\right.$, 
Table 4

Predicting academic outcomes: hierarchical regression-unstandardized regression weights at final block

\begin{tabular}{|c|c|c|c|c|c|c|}
\hline \multirow[t]{2}{*}{ Independent variables } & & \multicolumn{5}{|c|}{ Academic outcomes } \\
\hline & & $\begin{array}{l}\text { Positive } \\
\text { affect }\end{array}$ & Participation & Homework & GPA & $\begin{array}{l}\text { Summer } \\
\text { school }\end{array}$ \\
\hline \multirow[t]{3}{*}{ Constant } & $B$ & $1.86^{* * *}$ & $1.17^{* * *}$ & $1.87^{*}$ & 0.20 & $3.68^{* * *}$ \\
\hline & $S E$ & 0.31 & 0.22 & 0.77 & 0.18 & 0.77 \\
\hline & $\beta$ & - & - & - & - & - \\
\hline \multirow{3}{*}{ Female gender } & $B$ & 0.14 & $0.18^{*}$ & 0.15 & 0.13 & -0.37 \\
\hline & $S E$ & 0.09 & 0.09 & 0.43 & 0.10 & 0.37 \\
\hline & $\beta$ & 0.11 & 0.12 & 0.03 & 0.07 & \\
\hline \multirow[t]{3}{*}{ Hispanic race } & $B$ & $-0.18^{\dagger}$ & 0.04 & $-1.59^{* *}$ & $-0.31^{*}$ & $0.79^{\dagger}$ \\
\hline & $S E$ & 0.10 & 0.11 & 0.51 & 0.12 & 0.46 \\
\hline & $\beta$ & -0.13 & 0.02 & -0.23 & -0.14 & \\
\hline \multirow[t]{3}{*}{ White race } & $B$ & -0.12 & -0.21 & $-2.83^{* * *}$ & $-0.77^{* * *}$ & 0.81 \\
\hline & $S E$ & 0.14 & 0.14 & 0.67 & 0.16 & 0.58 \\
\hline & $\beta$ & -0.06 & -0.09 & -0.31 & -0.25 & \\
\hline \multirow[t]{3}{*}{ 1st Quarter GPA } & $B$ & 0.00 & $0.44^{* * *}$ & 0.13 & $0.84^{* * *}$ & $-1.35^{* * *}$ \\
\hline & $S E$ & 0.06 & 0.07 & 0.28 & 0.07 & 0.29 \\
\hline & $\beta$ & 0.00 & 0.46 & 0.03 & 0.66 & \\
\hline \multirow[t]{3}{*}{ Fall dependent variable } & $B$ & $0.51^{* * *}$ & $0.24^{* *}$ & $0.23^{* * *}$ & - & - \\
\hline & $S E$ & 0.08 & 0.08 & 0.05 & - & - \\
\hline & $\beta$ & 0.47 & 0.23 & 0.36 & - & - \\
\hline \multirow[t]{3}{*}{ Fall self-regulation } & $B$ & 0.01 & $0.06^{*}$ & $0.49^{* *}$ & $0.09^{*}$ & $-0.26^{*}$ \\
\hline & $S E$ & 0.04 & 0.04 & 0.17 & 0.04 & 0.15 \\
\hline & $\beta$ & 0.01 & 0.11 & 0.20 & 0.12 & 0.77 \\
\hline
\end{tabular}

${ }^{*} p<.05$.

${ }_{* * *}^{* *} p<.01$.

$p<.001$

${ }^{\dagger} p=.10$.

$F \Delta(1,154)=10.46, p<.01 ; B=0.08, \beta=0.17)$, and summer school referral, $\left(\chi^{2} \Delta(1, n=160)=4.68, p=.02 ; B=-0.21, \exp (B)=0.81\right)$, but not teacher report of participation, $R^{2} \Delta=.01, F \Delta(1,153)=1.55, p=.11, B=0.03, \beta=0.08$ or time spent in homework, $R^{2} \Delta=.01, F \Delta(1,153)=1.84, p=.09, B=0.15, \beta=0.10$. These findings suggest that the more complex coding that focuses on both detail of academic possible selves and number of strategies to attain them, may be capturing more relevant variance in behavior change.

Finally, added variance explained by self-regulation once count of strategies has been taken into account was examined by entering self-regulation as a final block in the regression analyses. Using this more stringent test (since number of strategies is also taken into account in the self-regulation coding), we found that the more complex self-regulation code added significantly to variance explained by simple count of achievement strategies to prediction of time spent doing homework $\left(R^{2} \Delta=.03\right.$, 
$F \Delta(1,152)=6.53, p<.01 ; B=0.57, \beta=0.24)$, and at trend level, to prediction of participation in class $\left(R^{2} \Delta=.01, F \Delta(1,152)=1.65, p=.10 ; B=0.06, \beta=0.10\right)$, but did not add to prediction of grades $\left(R^{2} \Delta=.00, F \Delta(1,152)=0.11, p<.37\right.$; $B=0.02, \beta=0.02$ ), or summer school referral (Wald test for possible-self-regulation score $=.20, \chi^{2}(1, n=160)$ for block $=0.20, p=.32 ; B=-0.09$, $\left.\exp (B)=0.92\right)$. Maintaining positive affect toward school $\left(R^{2} \Delta=.01, F \Delta(1,152)=1.98, p=.08\right.$; $B=-0.06, \beta=-0.12$ ) was related at a trend level, with the direction of effect suggesting a suppression effect of strategies on plausibility.

\subsection{Influence of possible selves on change in affect, behavior, and academic outcomes}

Number of achievement possible selves. Previous research on possible selves has tended to focus on the centrality of a possible self-domain by utilizing a count of the number of possible selves generated in a domain. To compare the explanatory power of self-regulation with that of centrality, we repeated the previously described regression analyses, using the number of academic possible selves rather than plausibility of possible-self-regulation in the final block. While count of achievement focused possible selves was related to teacher report of participation $(F \Delta(1,153)=3.73, p=.03 ; B=0.07, \beta=0.12)$, and grades $(F \Delta(1,154)=5.36$, $p=.01 ; B=0.10, \beta=0.12)$, it did not add significantly to prediction of maintaining positive affect toward school $(F \Delta(1,154)=.42, p=.26 ; B=0.02, \beta=0.05)$, time spent in homework $(F \Delta(1,153)=0.02, p=.90 ; B=0.02, \beta=0.01)$, or summer school referral $\left(\chi^{2} \Delta(1, n=160)=0.33, p=.57 ; B=-0.09, \exp (B)=0.92\right)$.

As might be expected, once count of achievement possible selves is taken into account, self-regulation added significantly to prediction of time spent in homework $(F \Delta(1,152)=9.82, p=.001 ; B=0.60, \beta=0.25)$ and summer school referral $\left(\chi^{2} \Delta(1, n=160)=2.68, p=.05 ; B=-.28, \exp (B)=0.76\right)$, and at a trend level self-regulation adds to the prediction of later academic outcomes-grades $(F \Delta(1,153)=1.90, p=.09 ; B=0.06, \beta=0.08)$; however once sum of achievement possible selves was taken into account, self-regulation did not add to prediction of classroom participation $(F \Delta(1,152)=1.09, p=.15 ; B=0.04, \beta=0.07)$, and neither sum of achievement related possible selves nor the more complex coding of self-regulation predicted maintenance of positive affect toward school $(F \Delta(1,152)=0.01, p=.47 ; B=-0.00, \beta=-0.01)$.

Number of balanced academic possible selves. We repeated the previously described analyses with balance in academic possible selves as the final block. Balance in academic possible selves was a significant predictor of increased homework $(F \Delta(1,153)=7.71, p<.01 ; B=1.09, \beta=0.20)$, but not of change in positive affect toward school $(F \Delta(1,154)=0.74, p=.20 ; B=0.07, \beta=0.06)$, teacher reported participation in class $(F \Delta(1,153)=1.03, \quad p=.16 ; \quad B=0.08, \quad \beta=0.06)$, GPA $(F \Delta(1,154)=0.20, p=.33 ; B=-0.04, \beta=-0.02)$, or referral to remedial summer school referral $\left(\chi^{2} \Delta(1, n=160)=1.04, p=.16 ; B=-0.34, \exp (B)=0.71\right)$.

As might be expected, once balance in achievement possible selves is taken into account, self-regulation added significantly to prediction of academic outcomes, GPA $(F \Delta(1,153)=7.79, p<.01 ; B=0.13, \beta=0.16)$, time spent in homework 
$(F \Delta(1,152)=3.23, p=.04 ; B=0.35, \beta=0.14)$, and at trend level, to summer school referral $\left(\chi^{2} \Delta(1, n=160)=1.95, p=.08 ; B=-0.24, \exp (B)=0.79\right)$, and teacher reported classroom participation $(F \Delta(1,152)=2.20, p=.07 ; B=0.06$, $\beta=0.10)$. Plausibility did not add significantly to maintaining positive affect, $F \Delta(1,154)=0.40, p=.42 ; B=-0.01 \beta=-0.02$.

\section{Discussion}

When asked to describe their expectations and concerns about what they will be like next year, even young teens have no trouble describing expected and feared possible selves - selves they expect to attain and those they would like to avoid. Asked if there is anything they are doing this year to get to be like their expected selves or avoid becoming like their feared selves, some youths have strategies, at least for some of their possible selves, while others do not. In our sample, the most common expectation is to do well in school and the most common concern is school failure. Yet, school underperformance is not uncommon among youths, particularly in low-income areas from which we sampled, as noted by other researchers (Ogbu, 1990) and as can be seen by the high rate of referral for remedial summer school. We focused on academic possible selves, asking if such possible selves could serve to increase academic success. Indeed, in our sample of primarily minority youths from high poverty schools and neighborhoods, those with plausibly self-regulating academic possible selves did have significantly greater chances of academic success. Plausibility of self-regulation was a significant predictor, even after previous academic attainment (in the form of first quarter GPA) and previous level of the specific dependent variable were controlled.

In spite of their overwhelming focus on attaining school success and avoiding school failure in their possible selves, the average youth in the sample experienced declining levels of school participation and involvement in homework over the course of the eighth grade year. In this context, youths whose academic possible selves could more plausibly serve a self-regulatory function were better able to stem this negative shift over time. Moreover, although the youths in this sample almost universally sought to do well in school, school grades did not change significantly over the school year in spite of these good intentions. Significant improvement occurred only for youths with plausibly self-regulatory academic possible selves.

This effect is important for two reasons, first, classroom participation, referral to summer school, and spring grade point average each was substantially predicted by fall grades, leaving a relatively small proportion of variability to be affected by other factors, including self-regulation efforts. Second, self-regulatory possible selves involved the kind of simple, concrete strategies that should be amenable to intervention efforts to support youths who have academic possible selves yet are not currently self-regulating.

Youths with academic possible selves that could plausibly serve a self-regulatory focus had academic outcomes that differed significantly from their peers, with improved classroom participation and grades and reduced chance of summer school 
referral, as well as increased time spent in homework compared to their peers. Our results point to the importance of considering not only the extent to which youths have academic possible selves or whether these possible selves 'balance' positive expectations with concerns but also whether these possible selves are likely to promote self-regulation as opposed to self-enhancement goals. Simply having many academic possible selves or balance in academic possible selves did not relate to improved classroom participation or grades or to reduced chances of summer school referral. Our findings suggest that youths can influence even long term and difficult to shift outcomes like time spent in homework, participation in class, grades and ultimately, school success, if they not only wish for success but also articulate how they will get there.

In this study we focused explicitly on plausibility of possible selves as self-regulators for the short term-next year, rather than more distal possible selves, such as adult or young adulthood. This is not to say that youths do not imagine the adults they would like to become. However, it seems less likely that these more distal possible selves serve self-regulatory functions for most youths. Self-regulation requires having action plans or strategies connected to self-relevant goals, and in our own work developing interventions to promote self-regulation (Oyserman, Terry, \& Bybee, 2002), we found that few low-income youths spontaneously make connections between current behaviors and adult visions. Another reason to focus on shorter term possible selves is that youths can obtain clearer feedback about their success in working toward shorter term expected selves (and avoiding shorter term feared selves) than they would be able to obtain about more distal possible selves. This is important because attaining feedback that signals success in moving toward short term plans and away from feared selves or anti-goals is both reinforcing in its own right and also provides youth with feedback about their likely success in working toward longer term goals such as adult possible selves (Carver, 2001).

In a study with undergraduates performing physical exertion tasks, Bandura and Cervione (1983) showed that performance improved only among participants who set a goal, felt competent about reaching it, obtained feedback about their current performance, and felt that current performance was disappointing compared to the goal. In this study, feedback was physiological. In our more naturalistic study, it is likely that feedback for classroom participation and grades and for time spent doing homework came from different sources - with the former coming from teachers and school and the latter coming from parents and internal standards. Further study is needed to understand potential influence of feedback source on self-regulation. Moreover, it was youths with plausible possible selves - those that included self-regulation strategies, who were able to improve performance. Our data suggest that if we wish to improve outcomes for low-income and minority inner city youths, we must help them link wishes, expectations, and concerns for their academic future with concrete strategies to take action.

Our study also highlights the social context of school and schooling. Girls participated more in school than boys, and African Americans outperformed non-African Americans, whether Hispanic or White in terms of grades, risk of referral to remedial 
summer school, and time spent doing homework. While the gender finding is not surprising (Eccles, Barber, Jozefowicz, Malenchuk, \& Vida, 1999), the positive finding for African Americans may perhaps surprise readers. However, for Detroit, where African Americans are the dominant group, this does not seem surprising. The finding does highlight the need to study self-regulation in a variety of real-world settings, over real time and with real-world limitations on change and malleability of outcomes. Although results were robust to reporting source, and have the advantage of use of naturalistic context and time lag, the use of a single sample is a limitation, and the current results must be considered preliminary until they can be replicated with other samples and in other settings. Our ongoing program of research aims at understanding the ways that social contexts can elicit or dampen effective self-regulation.

Our analyses suggest that having an achievement-related focus in self-concept provides some impetus to behavior and outcome change and that youth who also have a self-regulatory focus are better able to make change. We explored various operationalizations of self-regulation. Even taking a simple count of the number of strategies youths have devised to work toward their achievement-related expected possible selves and to avoid becoming like their feared achievement-related possible selves captures much of the predictive power of self-regulation. Although a variety of coding methods for self-regulation were useful in capturing change in behavior (time spent doing homework) and academic outcomes (GPA and summer school referral), the two methods differed in that only the simple count of strategies predicted positive change in affect toward school, and only the more complex coding of self-regulation predicted positive change in teacher reported behavior (classroom participation). That many findings are replicated across coding schemes suggests the robustness of connection between self-regulation and behavior change, the differences we do find suggest that future research should use methods for assessing self-regulation that fit the outcomes of interest.

\section{Appendix A. Next year possible selves}

Who will you be next year? Each of us has some image or picture of what we will be like and what we want to avoid being like in the future. Think about next year-imagine what you will be like, and what you will be doing next year.

- In the lines below, write what you expect you will be like and what you expect to be doing next year.

- In the space next to each expected goal, mark No (X) if you are not currently working on that goal or doing something about that expectation and mark Yes $(\mathrm{X})$ if you are currently doing something to get to that expectation or goal.

- For each expected goal that you marked Yes, use the space to the right to write what you are doing this year to attain that goal. Use the first space for the first expected goal, the second space for the second expected goal and so on. 


\begin{tabular}{lll}
\hline Next year, I expect to be & $\begin{array}{l}\text { Am I am doing } \\
\text { something to be } \\
\text { that way }\end{array}$ & $\begin{array}{l}\text { If yes, What I am doing now } \\
\text { to be that way next year }\end{array}$ \\
\cline { 2 - 3 } & No Y Yes & \\
\hline$(\mathrm{P} 1)$ & & \\
\hline$(\mathrm{P} 2)$ & & \\
\hline$(\mathrm{P} 3)$ & & \\
\hline
\end{tabular}

In addition to expectations and expected goals, we all have images or pictures of what we do not want to be like; what we do not want to do or want to avoid being. First, think a minute about ways you would not like to be next year-things you are concerned about or want to avoid being like.

- Write those concerns or selves to-be-avoided in the lines below.

- In the space next to each concern or to-be-avoided self, mark No (X) if you are not currently working on avoiding that concern or to-be-avoided self and mark Yes (X) if you are currently doing something so this will not happen next year.

- For each concern or to-be-avoided self that you marked Yes, use the space at the end of each line to write what you are doing this year to reduce the chances that this will describe you next year. Use the first space for the first concern, the second space for the second concern and so on.

\begin{tabular}{lll}
\hline $\begin{array}{l}\text { Next year, I want to avoid } \\
\text { being/doing }\end{array}$ & $\begin{array}{l}\text { Am I doing } \\
\text { something to } \\
\text { avoid this }\end{array}$ & $\begin{array}{l}\text { If yes, What I am doing now } \\
\text { to avoid being that way next } \\
\text { year }\end{array}$ \\
\hline (P5) & Yes & \\
\hline$(\mathrm{P} 6)$ & & \\
\hline$(\mathrm{P} 7)$ & & \\
\hline$(\mathrm{P} 8)$ & & \\
\hline
\end{tabular}

\section{References}

Aloise-Young, P., Hennigan, K., \& Leong, C. (2001). Possible selves and negative health behaviors during early adolescence. Journal of Early Adolescence: Special Issue, 21, 158-181.

Arroyo, C., \& Zigler, E. (1995). Racial identity, academic achievement, and the psychological well-being of economically disadvantaged adolescents. Journal of Personality and Social Psychology, 69, 903-914.

Bandura, A., \& Cervione, D. (1983). Self-evaluative and self-efficacy mechanisms governing the motivational effects of goal systems. Journal of Personality and Social Psychology, 45, 1017-1028. 
Brickman, P., \& Bulman, R. (1977). Pleasure and pain in social comparison. In J. Suls \& R. Miller (Eds.), Social comparison processes: Theoretical and empirical perspectives (pp. 149-186). Washington, DC: Hemisphere.

Brown, J. (1998). The self. New York, NY: McGraw Hill.

Cameron, J. (1999). Social identity and the pursuit of possible selves: Implications for the psychological well-being of university students. Group Dynamics, 3, 179-189.

Carver, C. (2001). Self-regulation. In A. Tesser \& N. Schwarz (Eds.), Blackwell handbook of social psychology (pp. 307-328). Malden, MA: Blackwell Press.

Cernkovich, S., \& Giordano, P. (1992). School bonding, race, and delinquency. Criminology, 30, 261291.

Coats, E., Janoff-Bulman, R., \& Alpert, N. (1996). Approach versus avoidance goals: Differences in selfevaluation and well-being. Personality and Social Psychology Bulletin, 22, 1057-1067.

Cohen, J. (1982). Set correlation as a general multivariate data-analysis method. Multivariate Behavioral Research, 17, 301-341.

Eccles, J., Barber, B., Jozefowicz, D., Malenchuk, O., \& Vida, M. (1999). Self-evaluations of competence, task values, and self-esteem. In N. Johnson (Ed.), Beyond appearance: A new look at adolescent girls (pp. 53-83). Washington, DC: American Psychological Association.

Finn, J., Pannozzo, G., \& Voelk1, K. (1995). Disruptive and inattentive-withdrawn behavior and achievement among fourth graders. Elementary School Journal, 95, 421-434.

Gollwitzer, P. (2002). March. The Control of the unwanted. Colloquium presented at The University of Michigan, Department of Psychology, Ann Arbor, MI.

Gollwitzer, P. (1996). The volitional benefits of planning. In P. Gollwitzer (Ed.), The psychology of action: Linking cognition and motivation to behavior (pp. 287-312). New York, NY: The Guilford Press.

Gonzales, M., Burgess, D., \& Mobilio, L. (2001). The allure of bad plans: Implications of plan quality for progress toward possible selves and postplanning energization. Basic and Applied Social Psychology, $23,87-108$

Harter, S. (1985). Processes underlying the construction, maintenance and enhancement of self-concept formation in children. In J. Suls \& A. Greenwald (Eds.), Psychological perspectives on the self (Vol. 3, pp. 132-182). Hillsdale, NJ: Erlbaum.

Higgins, E. T. (1996). The "self-digest": Self-knowledge serving self-regulatory functions. Journal of Personality and Social Psychology, 71, 1062-1083.

Kao, G. (2000). Group images and possible selves among adolescents: Linking stereotypes to expectations by race and ethnicity. Sociological Forum, 15, 407-430.

Kemmelmeier, M., \& Oyserman, D. (2001). The ups and downs of thinking about a successful other: Selfconstruals and the consequences of social comparisons. European Journal of Social Psychology: Special Issue, 31(3), 311-320.

Kerpelman, J., \& Pittman, J. (2001). The instability of possible selves: Identity processes within late adolescents' close peer relationships. Journal of Adolescence, 24, 491-512.

Knox, M., Funk, J., Elliott, R., \& Bush, E. (2000). Gender differences in youths' possible selves. Youth and Society, 31, 287-309.

Markus, H., \& Nurius, P. (1986). Possible selves. American Psychologist, 41, 954-969.

Markus, H., \& Wurf, E. (1987). The dynamic self-concept. Annual Review of Psychology, 299-337.

Ogbu, J. (1990). Literacy and schooling in subordinate cultures: The case of Black Americans. In E. Lomotey (Ed.), Going to school: The African American experience (pp. 113-131). SUNY Series, Frontiers in Education.

Oyserman, D., \& Markus, H. R. (1990). Possible selves and delinquency. Journal of Personality and Social Psychology, 59, 112-125.

Oyserman, D., Terry, K., \& Bybee, D. (2002). A possible selves intervention to enhance school involvement. Journal of Adolescence, 24, 313-326.

Oyserman, D. (2001). Self-concept and identity. In A. Tesser \& N. Shwarz (Eds.), Blackwell handbook of social psychology (pp. 499-517). Malden, MA: Blackwell Press.

Rawsthorne, L., \& Elliott, A. (1999). Achievement goals and intrinsic motivation: A meta-analytic review. Personality and Social Psychology Review (3), 326-344. 
Schafer, J., \& Graham, J. W. (2002). Missing data: Our view of the state of the art. Psychological Methods, 7, 147-177.

Shepard, B., \& Marshall, A. (1999). Possible selves mapping: Life-career exploration with young adolescents. Canadian Journal of Counseling, 33, 37-54.

Steele, C. (1997). A burden of suspicion: How stereotypes shape the intellectual identities and performance of women and African-Americans. American Psychologist, 52, 613-629.

Taylor, S., Neter, E., \& Wayment, H. (1995). Self-evaluation processes. Personality and Social Psychology Bulletin, 21, 1278-1287.

US Bureau of the Census (2000). Census 2000 [On-line]. Retrieved January 30, 2003. Available: http:// www.census.gov. 